\title{
Unbalanced Magnetic Pull Effect on Stiffness Models of Active Magnetic Bearing due to Rotor Eccentricity in Brushless DC Motor Using Finite Element Method
}

\author{
Bangcheng Han, ${ }^{1,2}$ Shiqiang Zheng, ${ }^{1,2}$ and Xiquan Liu ${ }^{1}$ \\ ${ }^{1}$ School of Instrument Science and Optoelectronics Engineering, Beihang University, Beijing 100191, China \\ ${ }^{2}$ Science and Technology on Inertial Laboratory, Beijing 100191, China \\ Correspondence should be addressed to Shiqiang Zheng; zhengshiqiang@buaa.edu.cn
}

Received 24 February 2013; Revised 6 June 2013; Accepted 13 June 2013

Academic Editor: Sarp Adali

Copyright (C) 2013 Bangcheng Han et al. This is an open access article distributed under the Creative Commons Attribution License, which permits unrestricted use, distribution, and reproduction in any medium, provided the original work is properly cited.

We firstly report on an investigation into the unbalanced magnetic pull (UMP) effect on the static stiffness models of radial active magnetic bearing (RAMB) in brushless DC motor (BDCM) in no-loaded and loaded conditions using the finite element method (FEM). The influences of the UMP on the force-control current, force-position, current stiffness, and position stiffness of RAMB are clarified in BDCM with $100 \mathrm{~kW}$ rated power. We found the position stiffness to be more susceptible to UMP. The primary source of UMP is the permanent magnets of BDCM. In addition, the performance of RAMB is affected by the UMP ripples during motor commutation and also periodically affected by the angular position of rotor. The characteristic curves of RAMB force versus control current (or rotor position) and angular position of rotor affected by the UMP are given. The method is useful in design and optimization of RAMB in magnetically suspended BDCMs.

\section{Introduction}

The number of commercial/industrial applications for magnetic bearings is large and still growing because of the unique advantages: oil-free operation, vibration control, and on-line monitoring. Nowadays, magnetic bearings have been widely used in refrigeration compressors [1], turbo expanders, blower industry (specifically in the wastewater treatment area), pumps, and high-speed machines [2-5]. These systems are composed with magnetic bearings (MBs) and motor, and the different components are assembled on the rotor shaft which is supported by the MBs. The rotor supported by the MBs would be naturally combined by the mechanical model. Due to manufacturing imperfectness of mechanical parts and/or the use of magnetic bearings in high-speed motors, the rotor eccentricity is inevitable. The magnetic field in motors will create tangential electromagnetic forces on the rotor which will produce torque. The radial forces named as unbalanced magnetic pull (UMP) [6] are generated at the same time in which case the UMP is developed and in interaction with the rotor supported by magnetic bearings and they may cause significant effects on the static mathematical model of magnetic bearings. An analytical model for analyzing permanent magnet (PM) motors is presented for predicting of magnetic field and magnetic forces including UMP [7]. A simple analytical model which is able to account for the damping effects of a cage rotor on the UMP when the rotor is dynamically eccentric is presented [8]. The UMPs which act upon the rotor of a salient-pole synchronous generator due to the eccentric motion of the rotor shaft in the presence of magnetic field in no-loaded and loaded conditions are calculated using the finite element method [9]. Dynamic eccentricity up to $80 \%$ is put into the model of a large brushless rare-earth permanent magnet motors model and a variety of simulations carried out to investigate the UMP [10]. A general analytical model is developed to predict the UMP, which results in permanent-magnet brushless ac and $\mathrm{dc}$ machines having a diametrically asymmetric disposition of slots and phase windings [11]. An investigation on the UMP in ferrite-magnet fractional-slot brushless permanentmagnet motors due to either magnetic asymmetry or static rotor eccentricity is reported [12]. An analytic model for 


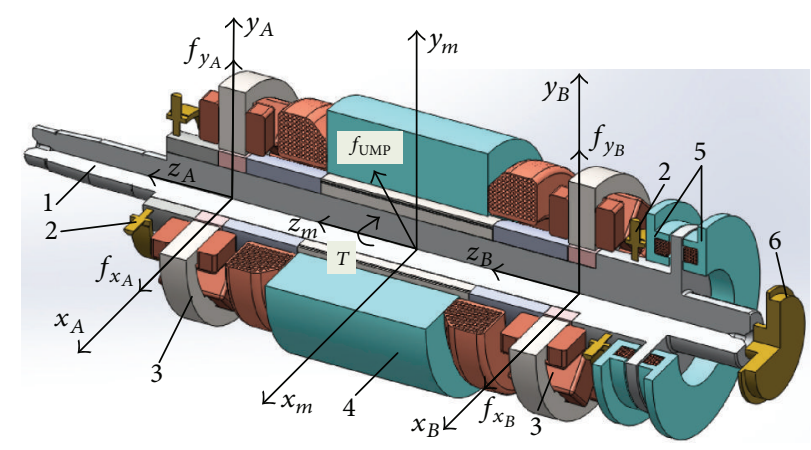

FIGURE 1: The configuration of BDCM which is supported by AMBs. (1) Rotor, (2) radial position sensors, (3) RAMB, (4) BDCM, (5) axial $\mathrm{AMB}$, and (6) axial position sensor.

analyzing the UMP induced by electromagnetic structure and drive current of the BDCM is presented, and the model can simplify effectively the analysis procedure [13]. The analytical justifications for the use of a numerical impulse method to calculate the effects of the slot harmonics on the UMP are presented [14]. Maxwell stress tensor (MST) method is used to compute the UMP based on the $2 \mathrm{D}$ finite element (FE) calculation [15]. The UMP in a threephase generator, caused by relative eccentricity, is calculated theoretically, and its effect on vibration of an eccentric rotor is studied [16]. The vibration sources of rotor in permanent magnet (PM) machine include mainly the centrifugal force generated by eccentricity and the UMP are reported. The finite element analysis combined with the Newmark method was used to calculate the nonlinear unbalance response due to eccentricity and the unbalanced magnetic pull [17]. Influences of rotor mass eccentric on suspension performance of bearingless switched reluctance motors were analyzed [18]. An on-line identification method of suspension force and magnetic unbalance pull force parameters in buried-type IPM bearingless motors has been presented [19]. A sort of beat appears in monitored radial displacements, caused by the interaction between the unbalance response of the rotor, and the UMP in induction motor is reported [20].

The emphases of the literatures mentioned previously are the analytical model of UMP and its effect on vibration, but few literatures focus on the UMP's effects on the stiffness models of AMB. The magnetic forces have been computed from the results of static magnetic field analysis. Thus, the potential circulating currents in the windings and eddy currents in conducting parts caused by eccentric rotor motion do not affect the magnetic forces, but they will make the core hotter. The main scope of this paper is to calculate and analyze the static UMP which can have an effect on the performance of radial active magnetic bearing (RAMB) due to static rotor eccentricity in BLDCM which is supported by AMBs. The UMP in $100 \mathrm{~kW}$ BLDCM is calculated owning to the static rotor eccentricity in no-loaded and loaded conditions by using FEM, and the performance of the RAMB is also analyzed by the characteristic curves of force-control current and force-position. Then, the influences of the UMP on the force-control current, the force-position, the current stiffness, and the position stiffness of RAMB are analyzed. The method is useful in design and optimization of RAMB in the magnetically suspended PM motor's design stage.

\section{Analysis of the UMP Effect on Characteristics of the RAMB}

The configuration of a BDCM which is supported by two RAMBs and a pair of axial AMBs is shown in Figure 1, and the configurations of BDCM and RAMB are shown in Figure 2. In BDCMs, the motor torque $T$ and the UMP $f_{\mathrm{UMP}}$ are produced due to the rotor eccentricity, and the UMP $f_{\mathrm{UMP}}$ will affect the characteristics of RAMBs.

From Figure 2(b), the non-linear net magnetic force [21] that is exerted on the rotor in differential driving modes can be given for $x$-axis as

$$
f_{x}=\frac{1}{4} \mu_{0} n^{2} A\left[\frac{\left(i_{0}+i_{x}\right)^{2}}{\left(s_{0}-x\right)^{2}}-\frac{\left(i_{0}-i_{x}\right)^{2}}{\left(s_{0}+x\right)^{2}}\right] \cos \beta
$$

with $k=(1 / 4) \mu_{0} n^{2} A \cos \beta$, where $\mu_{0}$ is permeability of free space $\left(\mu_{0}=4 \pi \times 10^{-7} \mathrm{Vs} / \mathrm{Am}\right), n$ is the number of turns in the electromagnet's coil, $A$ is the cross-section of the iron, $\beta$ is the angle under which the magnetic forces affect the rotor for each of the poles (in the case of RAMB with 8 poles, $\beta=$ $22.5^{\circ}$ ), the bias current $i_{0}$ is passed through both coils, the control current $i_{x}$ is added to the coil exerting forces in the positive direction and subtracted from the opposite coil, $s_{0}$ is the nominal air gap, and the displacement $x$ is the distance of rotor depart from its center position in $x$-axis direction.

Considering $x \ll s_{0}$ and $i_{x} \ll i_{0}$, (1) can be linearized by using Taylor's series. It yields the following typical AMB relation:

$$
f_{x}=\frac{4 k i_{0}}{s_{0}^{2}} i_{x}+\frac{4 k i_{0}^{2}}{s_{0}^{3}} x=k_{i} i_{x}+k_{s} x
$$

where $k_{i}=4 k i_{0} / s_{0}^{2}$ is the current stiffness and $k_{s}=4 k i_{0}^{2} / s_{0}^{3}$ is the displacement stiffness. The two kinds stiffness are constants depending on the magnetic bearing geometry (air gap, dimensions, material, and the coil turns) and the bias current without considering the UMP. 


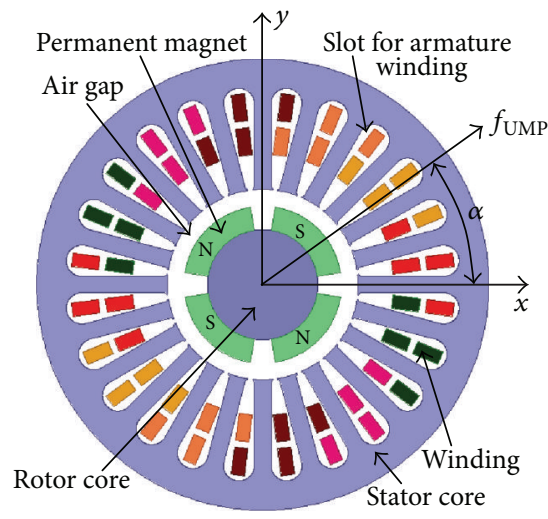

(a)

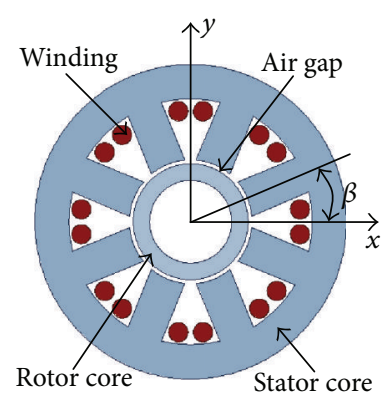

(b)

FIGURE 2: The configurations of the BDCM and the RAMB. (a) The configuration of BDCM. (b) The configuration of RAMB.

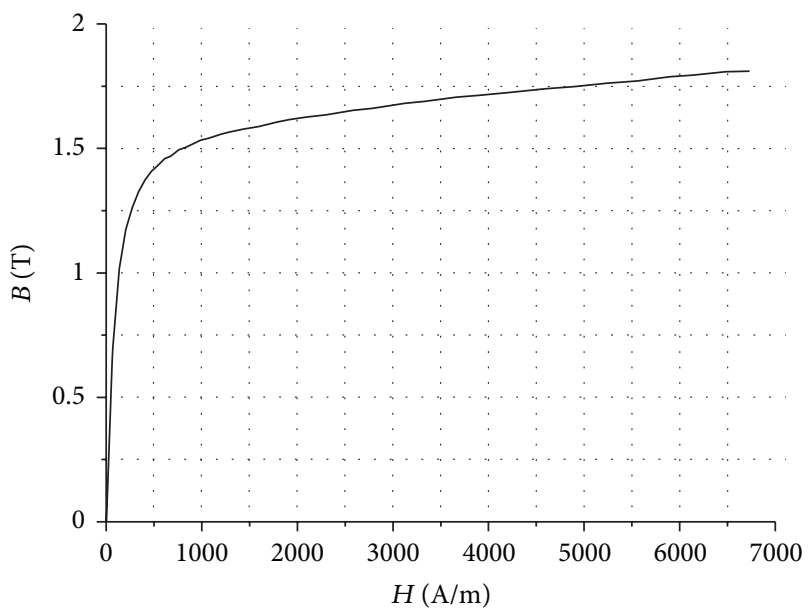

FIGURE 3: $B$ - $H$ curve for the ferromagnetic material.

The UMP will have an effect on the net magnetic force of RAMB in BDCM, and the net magnetic force discussed in (1) is rewritten as

$$
f_{x}^{\prime}=\frac{1}{4} \mu_{0} n^{2} A\left[\frac{\left(i_{0}+i_{x}\right)^{2}}{\left(s_{0}-x\right)^{2}}-\frac{\left(i_{0}-i_{x}\right)^{2}}{\left(s_{0}+x\right)^{2}}\right] \cos \beta+f_{\mathrm{UMP}} \cos \frac{\alpha}{2},
$$

where $\alpha$ is the angle between the vector of the UMP $f_{\mathrm{UMP}}$ and the $x$-axis. From (3), the net magnetic force, the current stiffness, and the displacement stiffness are affected by the UMP. There are two RAMBs in the system shown in Figure 1, and thereby the UMP is divided by 2 .

\section{Finite Element Model for Calculation of the UMP Effect on RAMB}

The eccentric motion of the rotor supported by AMBs in noloaded or loaded operation will result in the UMP which acts upon the rotor and consequently on the magnetic bearings of the BDCM. In this paper, the goal is to use the FEM to
TABLE 1: Designed parameters of the BDCM.

\begin{tabular}{lc}
\hline Parameters & Value \\
\hline Weight of the rotor, $(\mathrm{kg})$ & 23.6 \\
Number of pole pairs & 2 \\
Rated power, $(\mathrm{kW})$ & 100 \\
Rated voltage, $(\mathrm{V})$ & 480 \\
Maximum speed, (r/min) & 32000 \\
Number of stator slots & 24 \\
Connection & Star \\
Winding arrangement (series) & Double layer \\
Parallel branches of the stator winding & 4 \\
Rotor outer diameter, (mm) & 89 \\
Air gap length, (mm) & 4 \\
Stator inner diameter, (mm) & 97 \\
Axial length, $(\mathrm{mm})$ & 150 \\
\hline
\end{tabular}

TABLE 2: Designed parameters of the RAMB.

\begin{tabular}{lc}
\hline Parameters & Value \\
\hline Stator outer diameter, $(\mathrm{mm})$ & 228 \\
Stator inner diameter, $(\mathrm{mm})$ & 89.8 \\
Air gap length, $(\mathrm{mm})$ & 0.4 \\
Rotor outer diameter, $(\mathrm{mm})$ & 89 \\
Rotor inner diameter, $(\mathrm{mm})$ & 60 \\
Number of turns & 160 \\
Bias current, $(\mathrm{A})$ & 1 \\
Axial length, $(\mathrm{mm})$ & 16 \\
\hline
\end{tabular}

simulate the UMP and calculate the results of the UMP effect on the characteristics of RAMB in BDCM.

An example of magnetically suspended BDCM is given, and the design parameters of the BDCM and the RAMB are shown in Tables 1 and 2, respectively. The example is used to clarify the UMP effect on the characteristics of RAMB in magnetically suspended BDCM for no-loaded and loaded conditions, and so forth. 


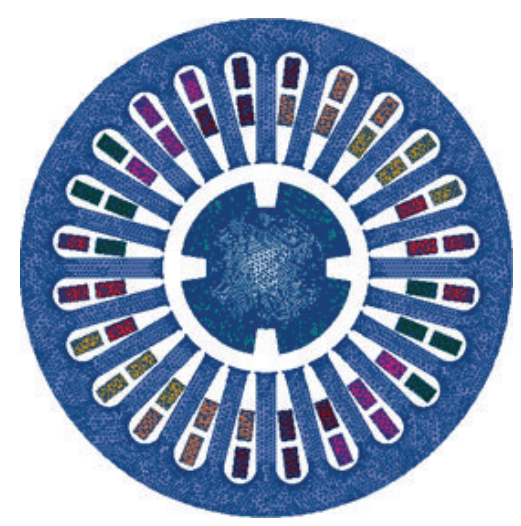

(a)

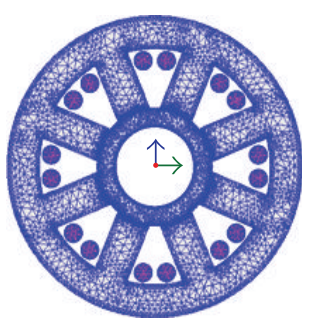

(b)

FIGURE 4: The 2-dimentional FE mesh model of BDCM and RAMB except the air. (a) The 2-dimentional FE mesh model of BDCM except the air. (b) The FE mesh model of RAMB except the air.

TABLE 3: UMP calculation at different loads.

\begin{tabular}{lc}
\hline Item & Stator current $(\mathrm{A})$ \\
\hline Without stator current in BDCM & 0 \\
No load in BDCM & 3.2 \\
Rated load in BDCM & 208 \\
\hline
\end{tabular}

\section{Simulation Results and Discussion}

4.1. The Load Currents in BDCM and Finite Element Model. The FEM simulations used to calculate the UMP's effects on characteristics of RAMB resulting from the eccentric of rotor for no-loaded and loaded conditions have been carried out in this section. As shown in Table 3, the UMP calculations at different loads are conducted in the following three cases.

(a) The UMP calculation without stator current which is used to clarify the UMP produced by the permanent magnet in BDCM effect on the characteristics.

(b) The UMP calculation for no-loaded condition which is used to clarify the UMP produced by the permanent magnet and no-loaded condition in BDCM effect on the characteristics.

(c) The UMP calculation for loaded condition which is used to clarify the UMP produced by the permanent magnet and rated loaded condition in BDCM effect on the characteristics.

The 2-dimensional (2D) finite element (FE) models of BDCM and RAMB are established and are shown in Figure 2 except the air. The $B-H$ curve of ferromagnetic material which is used for motor stator, RAMB's stator, and RAMB's rotor is shown in Figure 3 when the nonlinear analysis is considered. The software of Ansoft Maxwell is used to calculate electromagnetic field. The 2D FE mesh model of BDCM is shown in Figure 4(a), the air is not shown to give a better view of model, and there are 42748 elements totally. The FE mesh model of RAMB is shown in Figure 4(b), the air is also not shown, and there are 25942 elements in total. The vector potential boundary is available for use in Maxwell 2D.
The lines of magnetic flux for BDCM in loaded condition are shown in Figure 5(a). The lines of magnetic flux for RAMB with bias current are shown in Figure 5(b).

4.2. The Static Linearized Model of the RAMB and the UMP Produced by Permanent Magnet in BDCM. In the rotor center, the linearized model of RAMB without considering UMP through the 2D FEM is given in (4). The current stiffness $k_{i}=297.2 \mathrm{~N} / \mathrm{A}$, and the position stiffness $k_{s}=$ $-772020 \mathrm{~N} / \mathrm{m}$ :

$$
f_{x}=k_{i} i_{x}+k_{s} x=297.2 i_{x}-772020 x .
$$

The UMP is produced by the permanent magnet in BDCM without stator current. The following analysis considers the eccentricity and angular position of rotor. The eccentricity changes from $-200 \mu \mathrm{m}$ to $200 \mu \mathrm{m}$ and the angular position of motor rotor changes from $0^{\circ}$ to $180^{\circ}$. The characteristic curves of UMP-eccentricity-angular position of rotor are shown in Figure 6. The UMP is only calculated in $x$-axis as shown in Figure 2(a). It is obvious that the characteristic curves are linear; the UMP is determined by the eccentricity and is independent of the angular of motor rotor. The UMP is $38.7 \mathrm{~N}$ with the eccentricity of $-200 \mu \mathrm{m}$. The relationship between the UMP and the eccentricity can be given as follows:

$$
f_{\mathrm{UMP}}=k_{e p} e_{x}=-193220 e_{x}
$$

where $k_{e p}$ is the slope of $f_{\mathrm{UMP}}$ versus the eccentricity and the $e_{x}$ is the eccentricity. This is a disadvantage because the additional magnetic bearing force $(\mathrm{MBF})$ is necessary to overcome the negative slope coefficient, limiting the achievable control performance.

4.3. The Characteristic Curves of the MBF Affected by the UMP of BDCM with No-Loaded Condition. The relationship between the MBF of RAMB and the control current is calculated by FEM and is shown in Figure 7. The characteristic curves of MBF versus the control current which is 


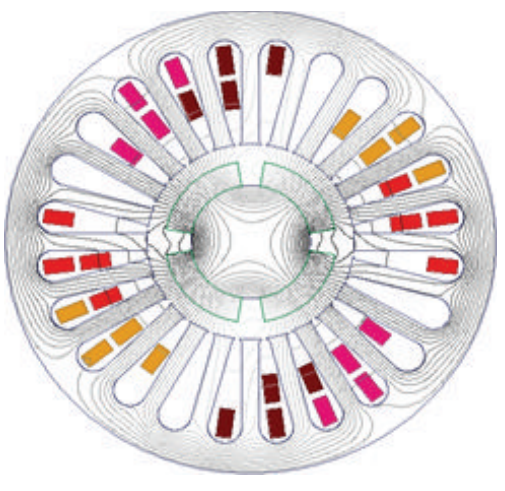

(a)

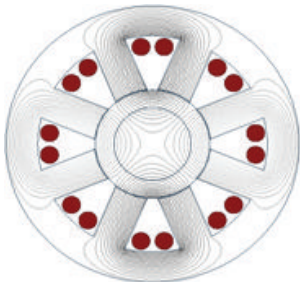

(b)

FIgure 5: The lines of magnetic flux for the BDCM and the RAMB. (a) The lines of magnetic flux for BDCM in loaded condition. (b) The lines of magnetic flux for RAMB with bias current.

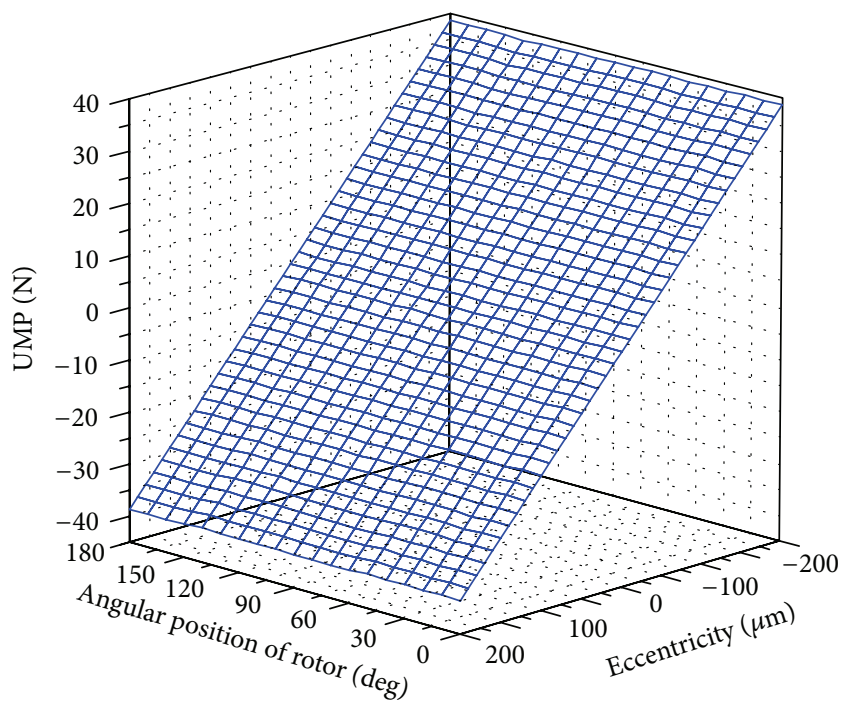

FIGURE 6: The UMP produced by permanent magnet in BDCM versus eccentricity and angular position of motor rotor.

affected by the UMP produced by the permanent magnet in BDCM for the different values of eccentricity are also shown in Figure 7. The current stiffness curves of RAMB are shown in Figure 8, and these 5 curves are coincident. It is obvious that the UMP only changes the amplitude of MBF without changing its current stiffness and the linear relationship between the MBF and the control current. The additional MBF produced by control current is necessary to overcome the UMP. For example, the $38.7 \mathrm{~N}$ provided by $\mathrm{RAMB}$ is necessary to overcome the UMP with eccentricity of $-200 \mu \mathrm{m}$. The mathematic model of the MBF versus control current affected by the UMP can be given as follows:

$$
f_{i}=k_{i} i_{x}+k_{e p} e_{x} \approx 297.2 i_{x}-193220 e_{x} .
$$

It is different from the characteristic curves of $\mathrm{MBF}$ versus control current affected by the UMP; the UMP affects the amplitude and linear relationship between the MBF versus rotor position of the RAMB, as the characteristic curves

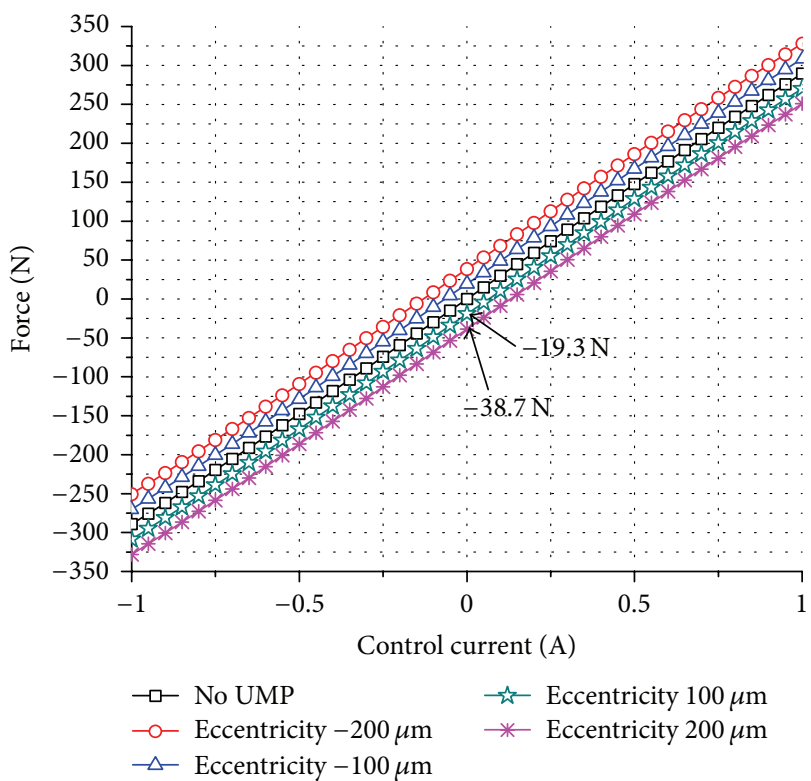

FIgURE 7: The characteristic curves of the MBF versus control current affected by the UMP which is produced by the PM in BDCM.

are shown in Figure 9. The UMP changes the equilibrium position of the RAMB; the additional control current of RAMB is necessary to maintain system stability. The position stiffness of RAMB is also varied by the UMP; and is shown in Figure 10. The absolute value of position stiffness in rotor center position increases from $772020 \mathrm{~N} / \mathrm{m}$ (No UMP) to $960346 \mathrm{~N} / \mathrm{m}$ (affected by UMP), namely, increases by $24.4 \%$. The position stiffness when UMP is not generated is different from those when the rotor is eccentric. The reason is there is no UMP when the rotor located its center, and only the torque is generated by the BDCM, but the UMP will be generated by the PM and (or) the control current in BDCM due to the rotor eccentric, then the characteristic curves of the MBF will be modified by the UMP. Thus, the position stiffness model is modified. The rate of the change of the $\mathrm{UMP}$ produced by BDCM versus the rotor eccentricity is the 


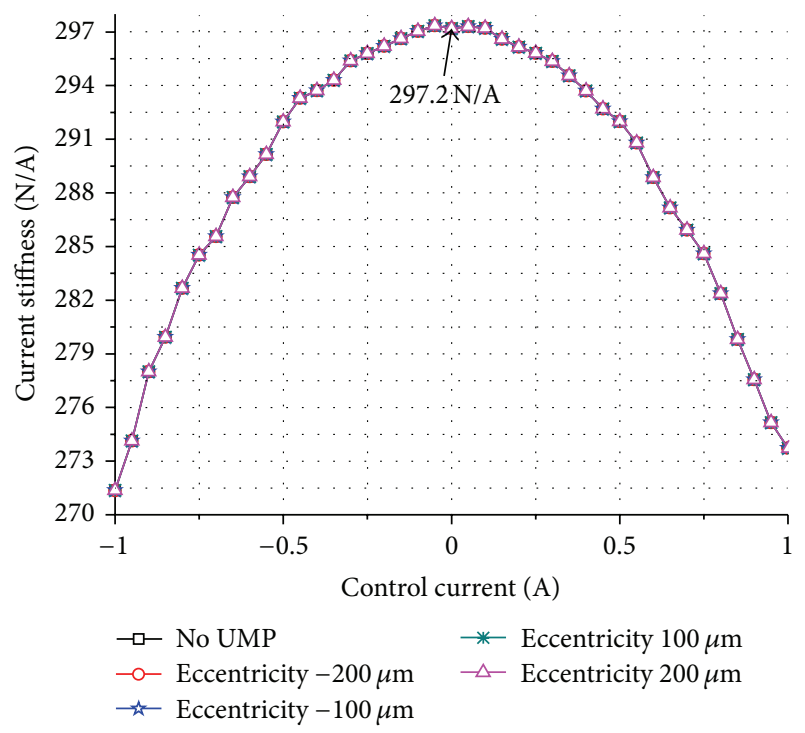

FIGURE 8: The characteristic curves of the current stiffness affected by the UMP which is produced by the PM in BDCM.

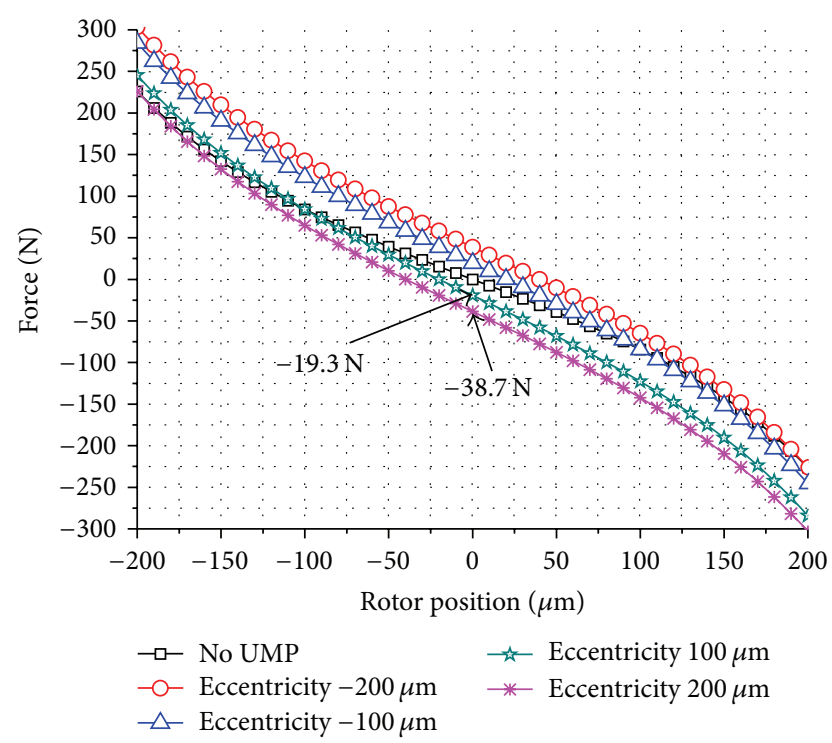

FIGURE 9: The characteristic curves of the MBF versus rotor position affected by the UMP of BDCM with no-loaded condition.

same, so it is equal between the eccentricities of $100 \mu \mathrm{m}$ and $200 \mu \mathrm{m}$. The position stiffness affected by the different values of eccentricity is the same, and their curves are coincident. The mathematic model of the MBF versus rotor position affected by the UMP can be given as follows:

$$
f_{s}=k_{s p} x+k_{e p} e_{x} \approx-960346 x-193220 e_{x} .
$$

Equations (6) and (7) are substituted into (3) considering the effect of the UMP produced by permanent magnet in BDCM in $x$-axis, which gives

$$
\begin{aligned}
f_{x}^{\prime} & =k_{i} i_{x}+k_{s p} x+2 k_{e p} e_{x} \cos 0^{\circ} \\
& =297.2 i_{x}-960346 x-386440 e_{x} .
\end{aligned}
$$

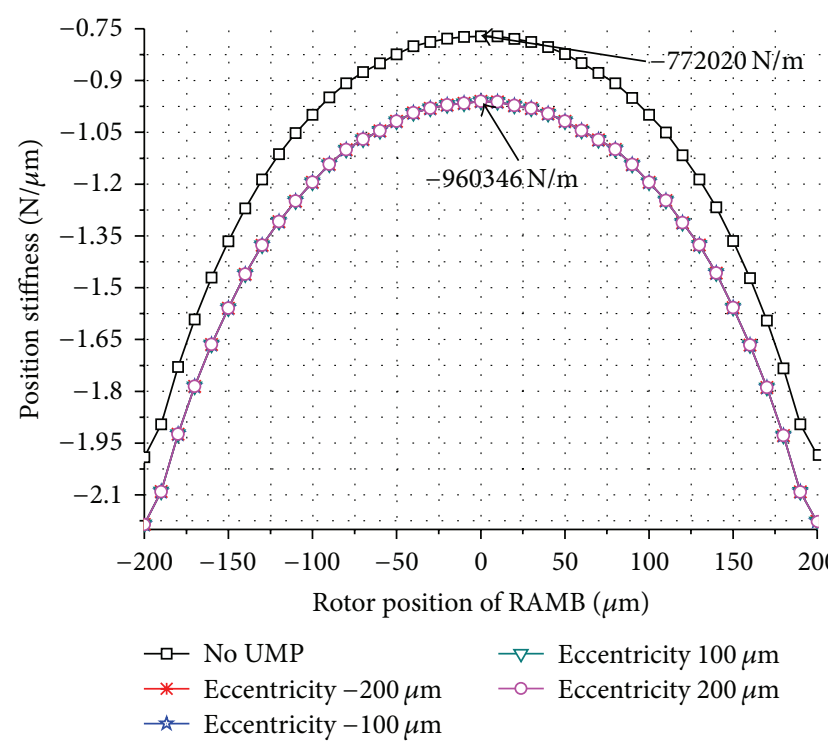

FIGURE 10: The characteristic curves of the position stiffness affected by the UMP of BDCM with no-loaded condition.

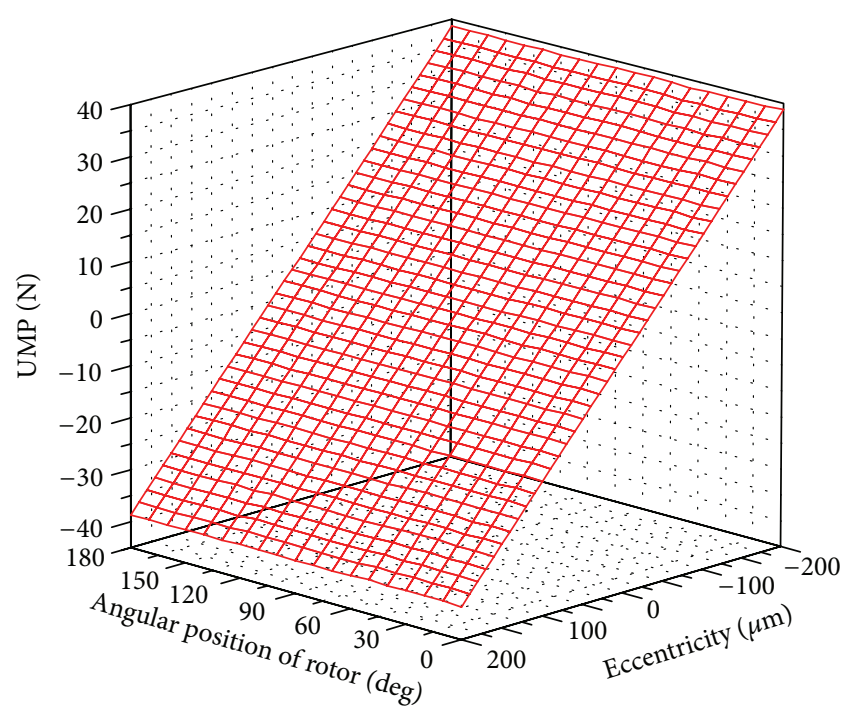

FIgURE 11: The UMP in no-loaded condition versus rotor eccentricity and angular position of motor rotor.

The UMP is produced by the permanent magnet and stator current (3.2 A) in BDCM for no-loaded operation. The following analysis considers the eccentricity and angular position of rotor. The eccentricity changes from $-200 \mu \mathrm{m}$ to $200 \mu \mathrm{m}$, and the angular position of motor rotor changes from $0^{\circ}$ to $180^{\circ}$. The characteristic curves of UMP-eccentricity-angular position of rotor are shown in Figure 11. The UMP is also calculated in $x$-axis as shown in Figure 2(a). It is obvious that the characteristic curves in noloaded condition are the same as the UMP produced by the permanent magnet in BDCM. The UMP produced by the stator current in no-loaded condition is very small and can be neglected for the large air gap. 


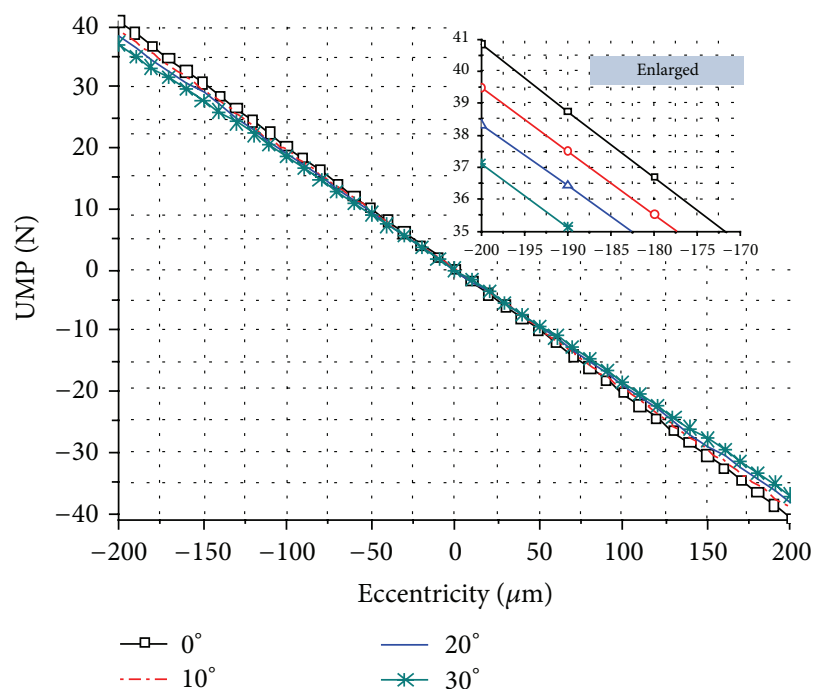

(a)

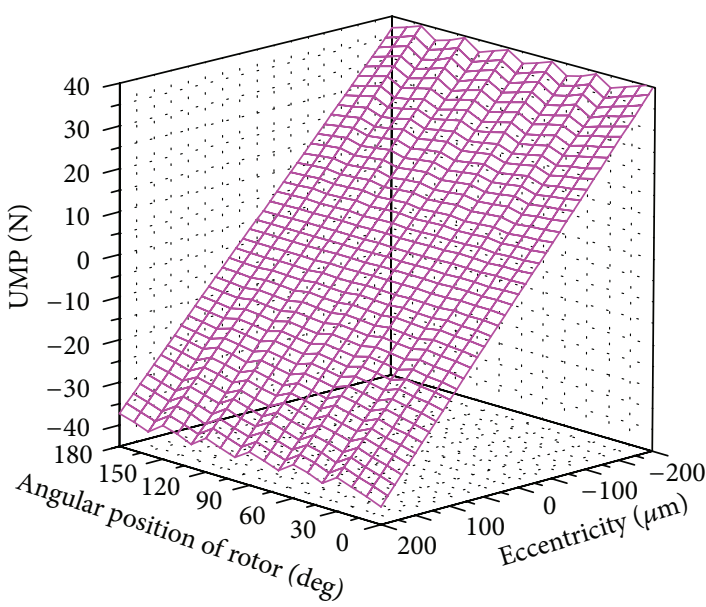

(b)

FIGURE 12: The UMP in loaded condition (stator current: $208 \mathrm{~A}$ ) versus eccentricity and angular position of motor rotor. (a) 2D. (b) 3D.

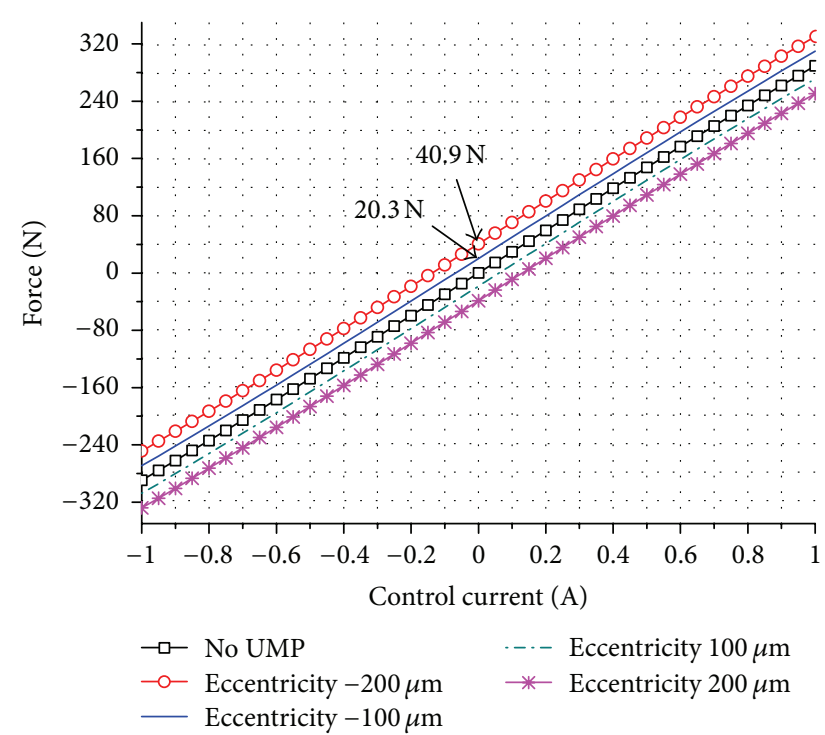

FIGURE 13: The characteristic curves of the MBF versus control current affected by the UMP for loaded operation in BDCM.

4.4. The Characteristic Curves of the MBF Affected by the UMP of BDCM in Loaded Condition. The previous analysis shows that the UMP for no-loaded condition or without stator current in BDCM is determined by the value of eccentricity and is independent of the angular of motor rotor, but the UMP for loaded (stator current: $208 \mathrm{~A}$ ) condition is not only affected by the eccentricity but also affected by the angular position of motor rotor with the larger value of eccentricity. The characteristic curves of the UMP in loaded condition versus eccentricity and angular position of motor rotor are shown in Figure 12. For example, the value of UMP will change from $37.1 \mathrm{~N}$ to $40.8 \mathrm{~N}$ with the eccentricity with

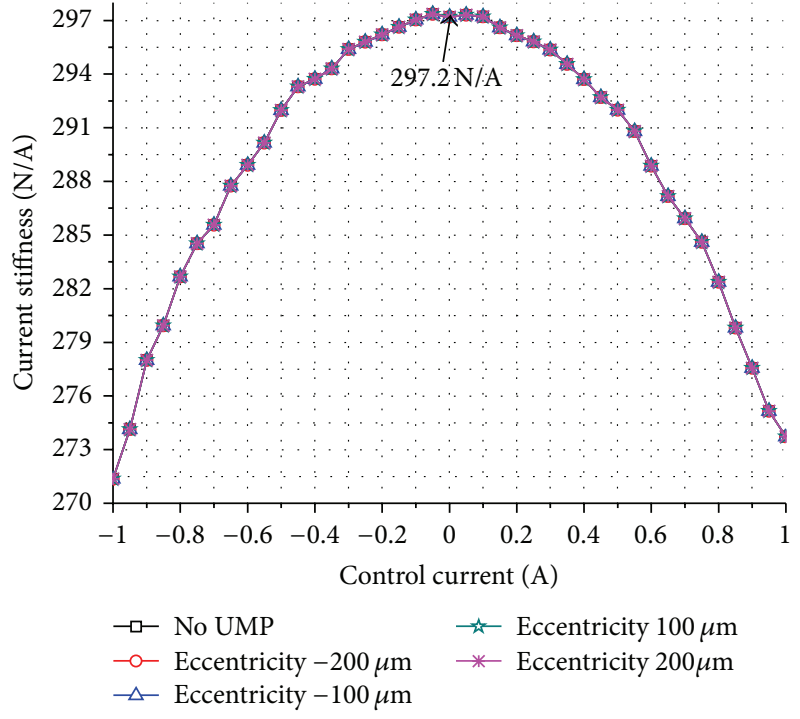

FIGURE 14: The characteristic curves of the current stiffness affected by the UMP for loaded operation in BDCM.

$-200 \mu \mathrm{m}$ when the motor rotates from $0-180$ degree, and the maximum error of UMP is $3.7 \mathrm{~N}$.

The UMP is produced by the permanent magnet and stator current in BDCM for loaded condition (stator current: $208 \mathrm{~A}$ ). The characteristic curves of MBF versus the control current affected by the UMP in loaded condition for the different values of eccentricity are shown in Figure 13, and the current stiffness curves of RAMB shown in Figure 14 are coincident. It is obvious that the UMP for loaded operation only changes the amplitude of MBF rather than changing its current stiffness and the linear relationship between the MBF and the control current. The additional MBF is necessary to overcome the UMP, such as $40.8 \mathrm{~N}$ provided by the 


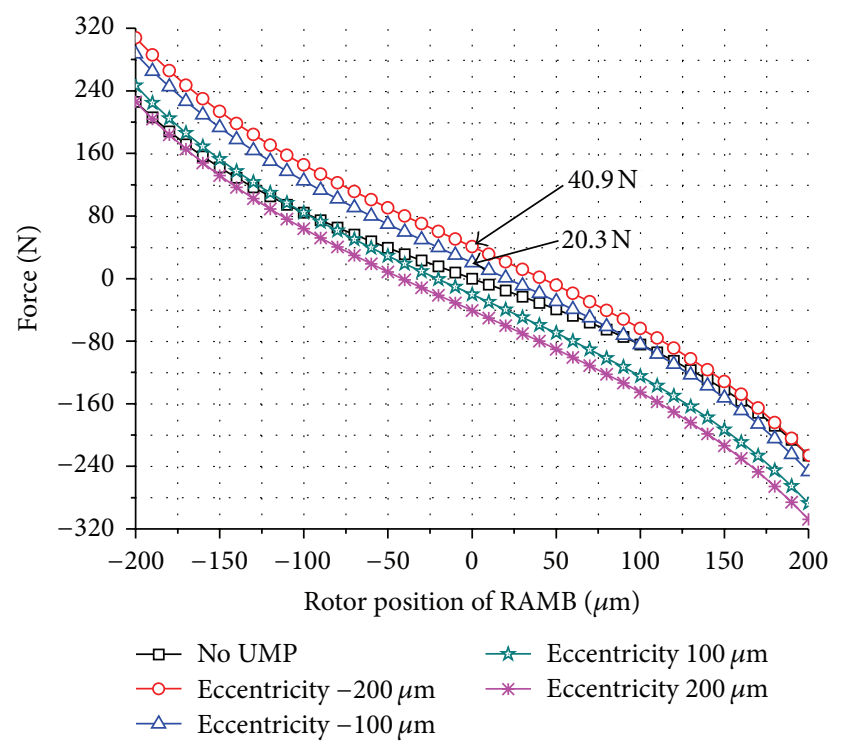

FIGURE 15: The characteristic curves of the MBF versus rotor position affected by the UMP for loaded operation in BDCM.

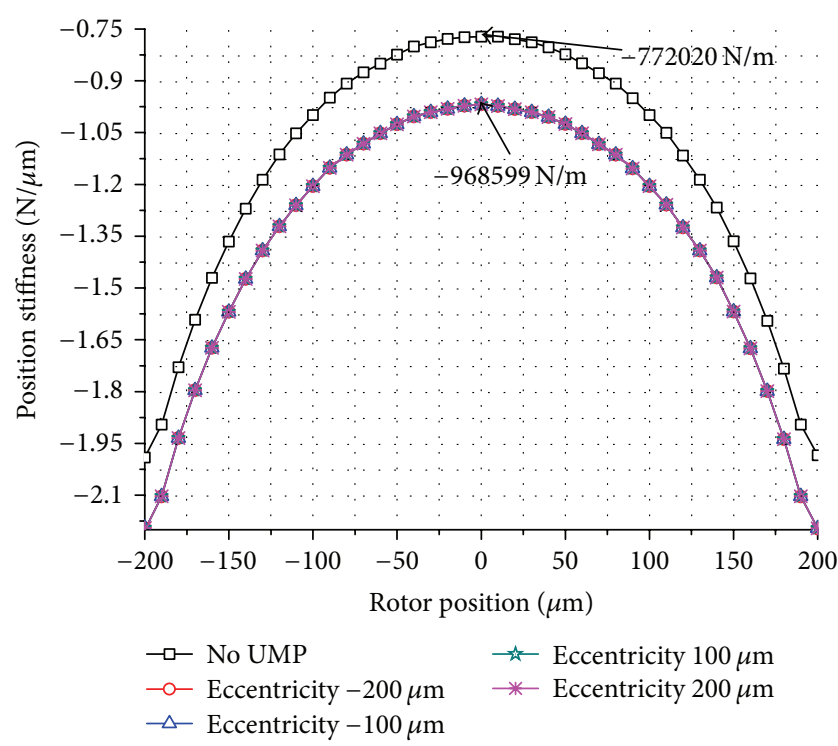

FIGURE 16: The characteristic curves of the position stiffness affected by the UMP for loaded operation in BDCM.

RAMB is necessary to overcome the UMP with eccentricity of $-200 \mu \mathrm{m}$. The UMP increases from $38.7 \mathrm{~N}$ to $40.8 \mathrm{~N}$ compared to the UMP produced by permanent magnet in $\mathrm{BDCM}$, and the difference is produced by the stator current in BDCM. The mathematic model of the MBF versus control current affected by the UMP in loaded condition can be given as follows:

$$
f_{i}=k_{i} i_{x}+k_{e p} e_{x} \approx 297.2 i_{x}-203041 e_{x}
$$

where $k_{e p}$ increases by $5 \%$ compared with (6); the calculation results show clearly that the UMP is mainly produced by the permanent magnet in BDCM.
It is also different from the characteristic curves of MBF versus control current affected by the UMP in BDCM for loaded operation; both the amplitude and the linear relationship between the MBF versus rotor position of the RAMB are affected by the UMP; the characteristic curves are shown in Figure 15. The UMP changes the equilibrium position of RAMB; the additional control current of RAMB is necessary to maintain system stability. The position stiffness of RAMB is also varied by the UMP; and is shown in Figure 16. The absolute value of position stiffness in rotor center position increases from $772020 \mathrm{~N} / \mathrm{m}$ (No UMP) to $968599 \mathrm{~N} / \mathrm{m}$ (affected by UMP), namely, increasing by $25.5 \%$. The position stiffness affected by the different value of eccentricity is also the same, and these curves are coincident. The mathematic model of the MBF versus rotor position affected by the UMP can be given as follows:

$$
f_{s}=k_{s p} x+k_{e p} e_{x} \approx-968599 x-203041 e_{x} .
$$

Equations (9) and (10) are substituted into (3) considering the effect of the UMP in BDCM for loaded operation in $x$ axis, which gives

$$
\begin{aligned}
f_{x}^{\prime} & =k_{i} i_{x}+k_{s p} x+2 k_{e p} e_{x} \cos 0^{\circ} \\
& =297.2 i_{x}-968599 x-406082 e_{x} .
\end{aligned}
$$

The commutation behavior of BDCM also affects the UMP. The control currents in BDCM will change according to the rotor position, and the PM of the BDMC is not axisymmetrical. Thus, the value of UMP will change at different commutation position due to the rotor eccentricity. So, the UMP during commutation will affect the MBF. The characteristic curves of the MBF versus control current and the MBF versus rotor position are shown in Figures 17 and 18 with different eccentricities. It can be calculated that the difference during commutation is $3.44 \mathrm{~N}$ for the MBF versus control current and $3.42 \mathrm{~N}$ for the MBF versus rotor position affected by the UMP in BDCM for loaded operation with eccentricity $-200 \mu \mathrm{m}$.

The characteristic curves of the UMP in loaded condition versus angular position of rotor for different eccentricities are shown in Figure 19. The value of UMP will change from $37.1 \mathrm{~N}$ to $40.8 \mathrm{~N}$ with the eccentricity of $-200 \mu \mathrm{m}$ when the motor rotates from 0-180 degree, the maximum difference of UMP is $3.7 \mathrm{~N}$, and the period of the UMP ripples is $30^{\circ}$. The reason is that the BDCM with 24 stator slots and 4 magnetic poles is calculated in this paper.

\section{Conclusions}

In this paper, the investigation of the UMP effect on the stiffness models of AMB due to the rotor static eccentricity in BDCM which is supported by AMBs is reported. The nonlinear FEM is used to calculate the UMP effect on the characteristics of RAMB in BDCM with $100 \mathrm{~kW}$ rated power in no-loaded and loaded conditions, such as the forcecurrent, the current stiffness, the force-displacement, and the displacement stiffness. 


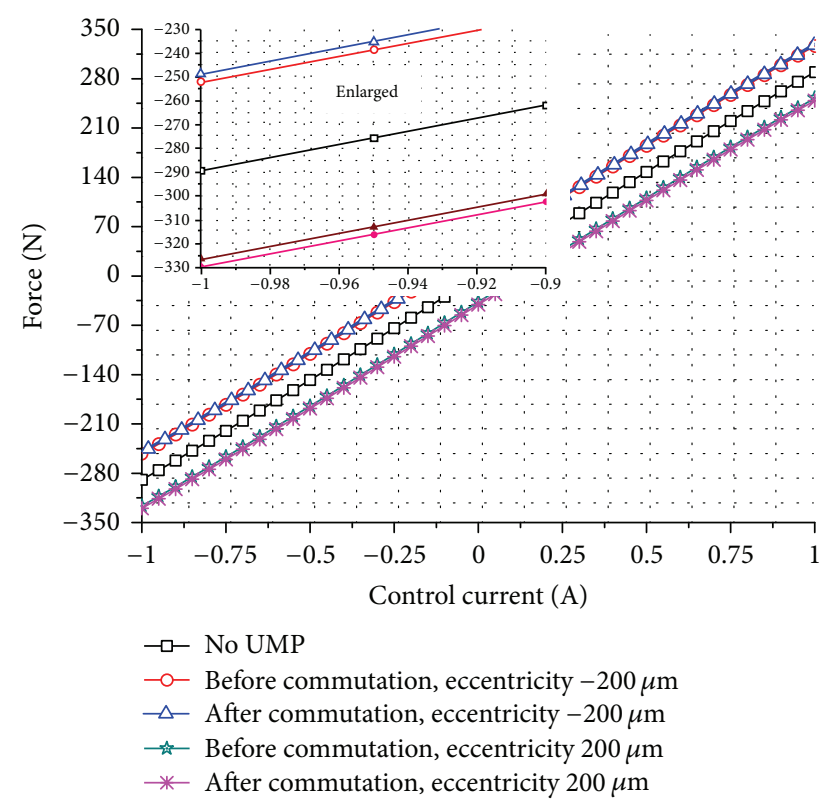

FIGURE 17: The characteristic curves of the MBF versus control current affected by the UMP during commutation in BDCM for loaded operation with eccentricity $\pm 200 \mu \mathrm{m}$.

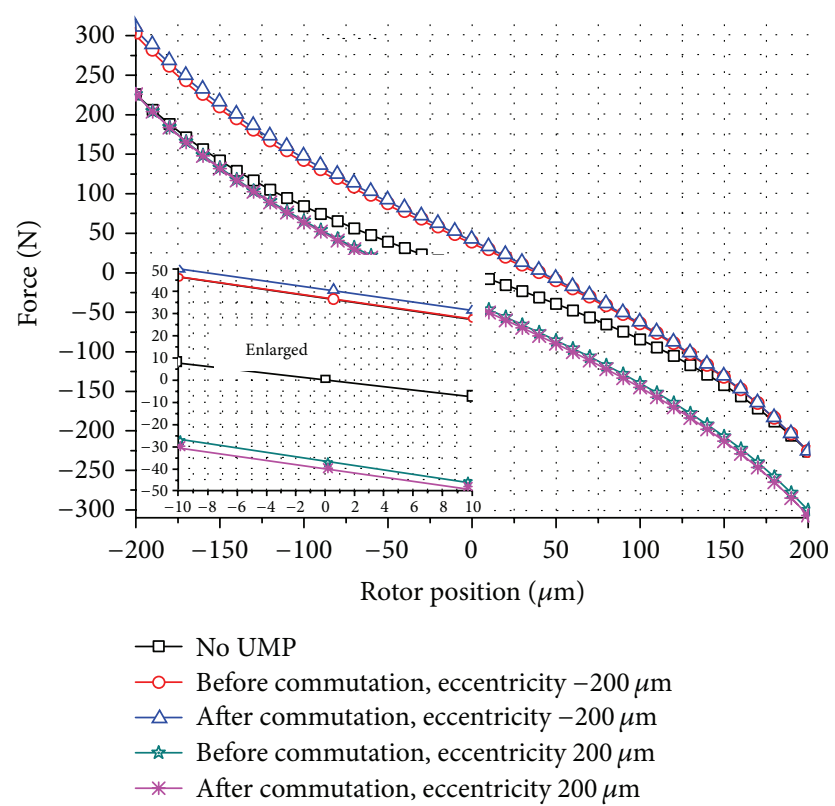

FIGURE 18: The characteristic curves of the MBF versus rotor position affected by the UMP during commutation in BDCM for loaded operation with eccentricity $\pm 200 \mu \mathrm{m}$.

The analytic results verified that the force-current, the force-displacement, and the displacement stiffness of RAMB are more susceptible to UMP, but the UMP has no effect on the current stiffness of RAMB. The primary source of UMP is the permanent magnets of BDCM, while the control current in BDCM has little influence on the UMP. For example, when the BDCM operates at full load, more than $95 \%$ of the UMP is produced by the permanent magnet of BDCM.

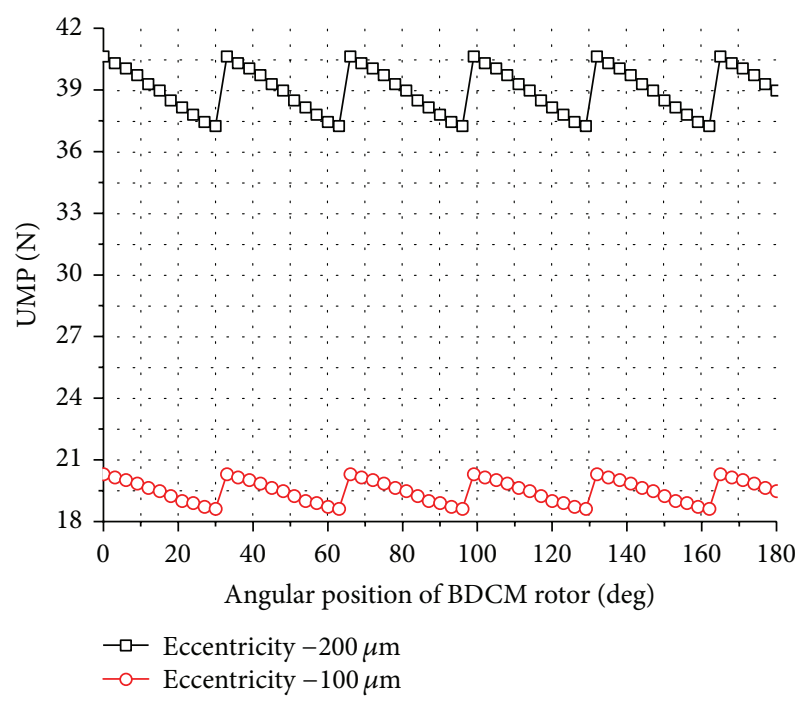

FIGURE 19: The characteristic curves of the UMP in loaded condition versus angular position of rotor for different eccentricity.

It will generate UMP ripples during motor commutation; the UMP after commutation is different from that before. The difference will affect the characteristics of the RAMB. The performance of RAMB is also periodically affected by the angular position of rotor and eccentricity. The amplitude of vibration is determined by the value of eccentricity, and the dynamic models would be considered in the future.

The method is useful in design and optimization of $A M B$ in magnetically suspended BDCMs and is of concern in design stage.

\section{Conflict of Interests}

The authors declare that they have no conflict of interests in this paper.

\section{Acknowledgments}

This work is supported by the National Basic Research Program of China (no. 2009CB724002) and in part by the Aviation Science Fund of China under Grant 2012ZB51019.

\section{References}

[1] H. Crowther and E. Smithart, "rictionless compressor technology: chillers cleaner, quieter, and more energy-efficient," HPAC Heating, Piping, Air Conditioning Engineering, vol. 76, no. 1, pp. 69-73, 2004.

[2] B. Blair and D. Weise, "Magnetic bearings," in Pumps and Systems, pp. 22-26, 1993.

[3] D. Eaton, J. Rama, and S. Singhal, "Magnetic bearing applications \& economics," in Proceedings of the Industry Applications Society 57th Annual Petroleum and Chemical Industry Conference (PCIC '10), pp. 1-9, September 2010.

[4] P. Imoberdorf, C. Zwyssig, S. D. Round, and J. W. Kolar, "Combined radial-axial magnetic bearing for a $1 \mathrm{~kW}, 500,000 \mathrm{rpm}$ permanent magnet machine," in Proceedings of the 22nd Annual 
IEEE Applied Power Electronics Conference and Exposition, pp. 1434-1440, March 2007.

[5] D.-K. Hong, K.-C. Lee, Y.-H. Jeong et al., "Magnetic field and rotordynamic analysis of $30 \mathrm{krpm} 220 \mathrm{~kW}$ rated high speed motor for blower supported magnetic bearing," in Proceedings of the 14th Biennial IEEE Conference on Electromagnetic Field Computation (CEFC '10), May 2010.

[6] A. Burakov and A. Arkkio, "Comparison of the unbalanced magnetic pull mitigation by the parallel paths in the stator and rotor windings," IEEE Transactions on Magnetics, vol. 43, no. 12, pp. 4083-4088, 2007.

[7] Z. J. Liu and J. T. Li, "Accurate prediction of magnetic field and magnetic forces in permanent magnet motors using an analytical solution," IEEE Transactions on Energy Conversion, vol. 23, no. 3, pp. 717-726, 2008.

[8] D. G. Dorrell, "Calculation of unbalanced magnetic pull in small cage induction motors with skewed rotors and dynamic rotor eccentricity," IEEE Transactions on Energy Conversion, vol. 11, no. 3, pp. 483-488, 1996.

[9] D. Žarko, D. Ban, I. Vazdar, and V. Jaríc, "Calculation of unbalanced magnetic pull in a salient-pole synchronous generator using finite-element method and measured shaft orbit," IEEE Transactions on Industrial Electronics, vol. 59, no. 6, pp. 25362549, 2012.

[10] D. G. Dorrell, M.-F. Hsieh, and Y. Guo, "Unbalanced magnet pull in large brushless rare-earth permanent magnet motors with rotor eccentricity," IEEE Transactions on Magnetics, vol. 45, no. 10, pp. 4586-4589, 2009.

[11] Z. Q. Zhu, D. Ishak, D. Howe, and J. Chen, "Unbalanced magnetic forces in permanent-magnet brushless machines with diametrically asymmetric phase windings," IEEE Transactions on Industry Applications, vol. 43, no. 6, pp. 1544-1553, 2007.

[12] D. G. Dorrell, M. Popescu, and D. M. Ionel, "Unbalanced magnetic pull due to asymmetry and low-level static rotor eccentricity in fractional-slot brushless permanent-magnet motors with surface-magnet and consequent-pole rotors," IEEE Transactions on Magnetics, vol. 46, no. 7, pp. 2675-2685, 2010.

[13] C. Bi, N. L. H. Aung, H. N. Phyu, Q. Jiang, and S. Lin, "Unbalanced magnetic pull induced by drive current in PMBLDC motor operation," in Proceedings of the International Conference on Electrical Machines and Systems (ICEMS '07), pp. 780-785, October 2007.

[14] P. Frauman, A. Burakov, and A. Arkkio, "Effects of the slot harmonics on the unbalanced magnetic pull in an induction motor with an eccentric rotor," IEEE Transactions on Magnetics, vol. 43, no. 8, pp. 3441-3444, 2007.

[15] L. Wang, R. W. Cheung, Z. Ma, J. Ruan, and Y. Peng, "Finiteelement analysis of unbalanced magnetic pull in a large hydrogenerator under practical operations," IEEE Transactions on Magnetics, vol. 44, no. 6, pp. 1558-1561, 2008.

[16] D. Guo, Y.-Y. He, and F.-L. Chu, "The calculation of unbalanced magnetic pull and its effect on vibration of an eccentric rotor," Engineering Mechanics, vol. 20, no. 2, pp. 116-121, 2003.

[17] T.-Y. Wang, F.-X. Wang, and C. Fang, "Vibration analysis of shafting of high speed permenant magnetic machinery," Journal of Vibration and Shock, vol. 30, no. 9, pp. 111-115, 2011.

[18] Q. Zhang, Z. Deng, and Y. Yang, "Compensation control of rotor mass eccentric in bearingless switched reluctance motors," Proceedings of the Chinese Society of Electrical Engineering, vol. 31, no. 21, pp. 128-134, 2011.

[19] M. Ooshima, T. Kurokawa, M. Sakagami, A. Chiba, M. A. Rahman, and T. Fukao, "An identification method of suspension force and magnetic unbalance pull force parameters in buriedtype IPM bearingless motors," in Proceedings of the IEEE Power Engineering Society General Meeting, pp. 1276-1279, June 2004.

[20] N. Amati and E. Brusa, "Vibration condition monitoring of rotors on AMB fed by induction motors," in Proceedings of the IEEE/ASME International Conference on Advanced Intelligent Mechatronics Proceedings, pp. 750-756, July 2001.

[21] B.-C. Han and Y.-H. Wu, "Calculation of forces and parameters of radial active magnetic bearing with eccentricities by finite element method," Journal of Harbin Institute of Technology, vol. 37, no. 2, pp. 187-189, 2005 (Chinese). 


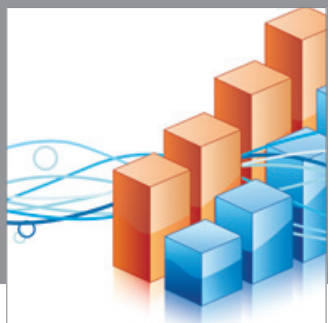

Advances in

Operations Research

mansans

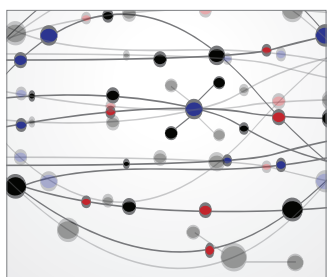

The Scientific World Journal
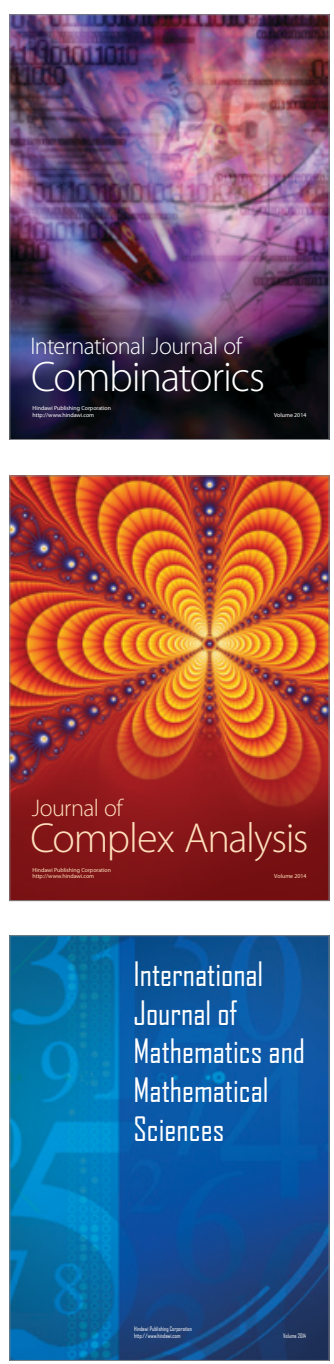
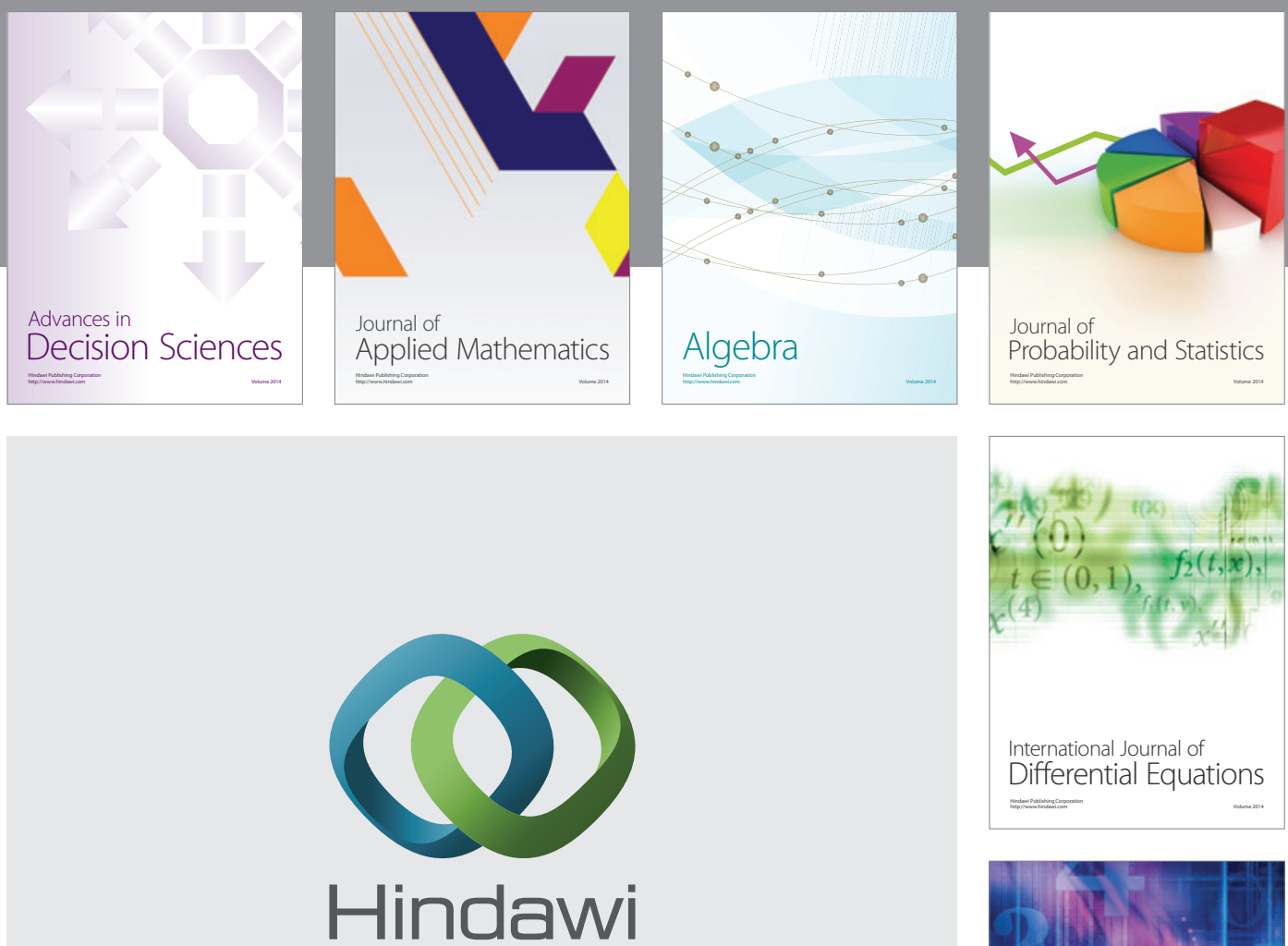

Submit your manuscripts at http://www.hindawi.com
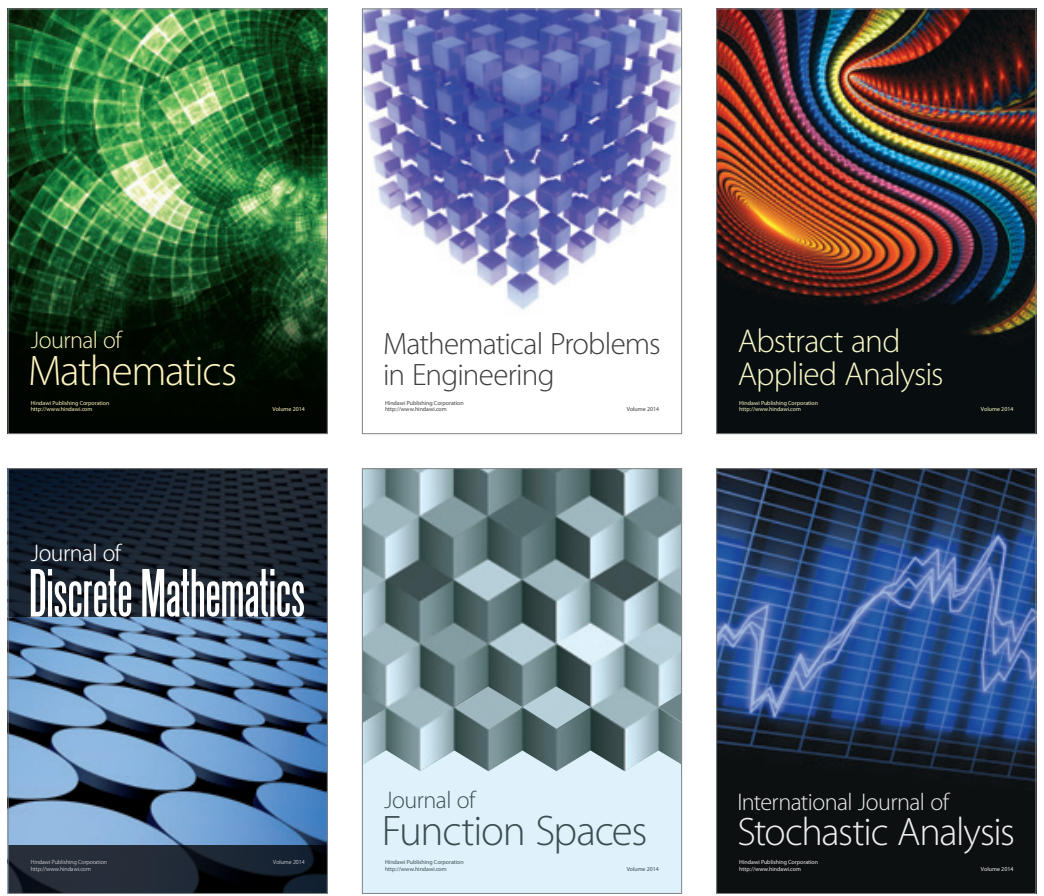

Journal of

Function Spaces

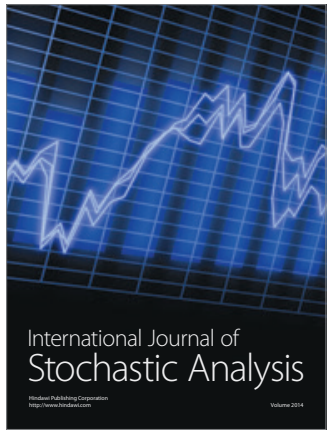

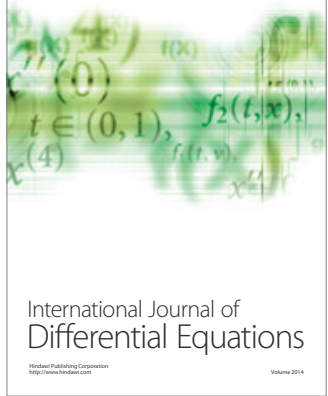
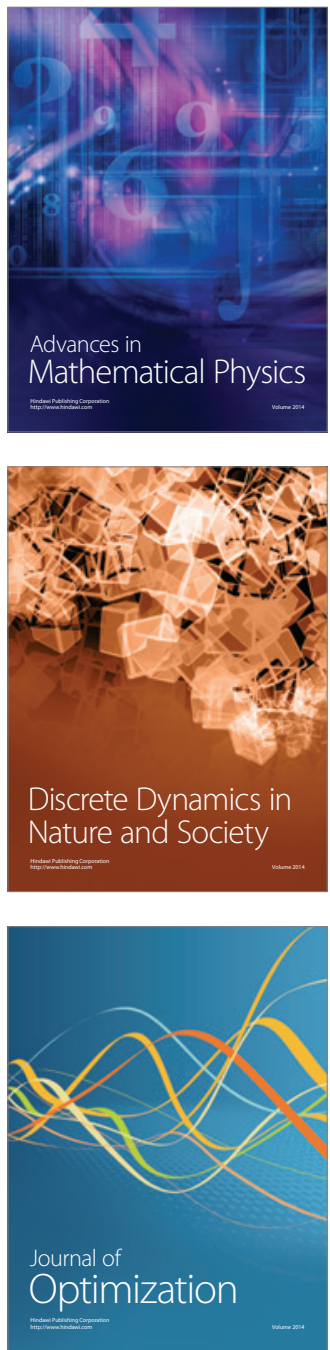